\title{
Variations in Maturity of Haddock in the Barents Sea in Relation to Year-class Strength, Age, Size, Sex and Area
}

\author{
Knut Korsbrekke \\ Institute of Marine Research, P. O. Box 1870 Nordnes \\ 5817 Bergen, Norway
}

\begin{abstract}
Data from the Norwegian Barents Sea bottom trawl surveys in February from 1985 through 1996 are used to analyse variations in haddock (Melanogrammus aeglefinus L.) maturity. Several link functions to estimate maturity ogives are compared. Due to the clustering of samples, both the goodness of fit and various other test statistics are calculated using an effective sampling size lower than the total number of samples. Length and yearclass strength are used as continuous explanatory variables while year, age, sex and area are class variables. A strong year effect was detected which appears to be related to the very large 1990 year-class. The year-class strength explains additional variation. That is: when abundance is high, the proportions mature are reduced for otherwise similar haddock (with respect to length, age, sex and area).

Both sex and area effects were significant. Males mature at younger ages and shorter lengths than females and there is a tendency for proportions mature to be lower in the eastern part of the Barents Sea.
\end{abstract}

Key words: Barents Sea, haddock, maturity

\section{Introduction}

Haddock is the second most important of the commercially exploited groundfish species in the Barents Sea. In the years covered by the analyses in this paper, the landings have ranged from 26000 tons in 1990 to a high of 173000 tons in 1996. The age 3 recruitment estimates (ICES, MS 1998) show a few strong year-classes with most year-classes more than one order of magnitude lower. A few year-classes, mostly neighbouring the strongest, seem to be around $20-50$ percent of a strong yearclass.

The main spawning areas are on the continental slopes in the western part of the Barents Sea and spawning takes place mostly towards the end of April (Solemdal et al., 1989, Solemdal et al., MS 1997).

Strong fluctuations in recruitment seem to be common for most haddock populations. Several authors have reported changes in maturity at length related to changes in growth. Reduced growth (usually coinciding with high abundance) increases the length at first spawning (Beacham, 1983;
Kovtsova, MS 1993; Templeman et al., 1978; Tormosova, 1983).

The questions initiating the work presented in this paper was: Is there something to gain from modelling the proportions mature as a function of more effects than the traditional length and age effects? More specifically: How large is the difference between males and females and are there any area effects or density dependent effects? In addition a more technical question: Is the choice of a functional form for the maturity ogive critical?

\section{Materials and Methods}

Data from the Norwegian Barents Sea bottom trawl survey collected from 1985 to 1996 are used in this study. The survey is a combined acoustic and bottom trawl survey for demersal fish and is conducted annually from the end of January to the beginning of March. The main aim of the survey is to map the spatial distributions and obtain indices of abundance for the most important commercially exploited demersal fish species in the Barents Sea. The target species are cod (Gadus morhua), haddock (Melanogrammus aeglefinus), golden 
redfish (Sebastes marinus), beaked redfish (Sebastes mentella) and Greenland halibut (Reinhardtius hippoglossoides). A description of the survey can be found in Jakobsen et al. (MS 1997).

The survey area was expanded in 1993 and because of this change to the time series, only data from the central region (A, B, C and D), which had good coverage in all years, were used (see Fig. 1).

The environmental conditions in the Barents Sea have varied substantially during the period studied. An indication of this variation is given in Fig. 2 which shows the average temperature from four different hydrographical sections from 1985 to 1996.

The effort and equipment employed in these years have changed (Jakobsen et al., MS 1997). The biggest change was the switch from bobbins to rockhopper ground gear in 1989. Another change was a reduction of mesh size in the codend from 40 to $22 \mathrm{~mm}$ in 1994 that introduced an increase in the abundance indices of small fish including haddock. In this work however, it is assumed that this change in mesh size had no effect on the observed proportions of mature haddock.

The data was analysed using PROC LOGISTIC in SAS/STAT (SAS Institute Inc., 1996). Proportions mature are modelled as a response probability using a link function (Nelder and Wedderburn, 1972):

$$
g(p)=a+b^{\prime} x
$$

The link functions used in these analyses are the logit (1), probit (2) and complementary log-log (3) functions:

$$
\begin{gathered}
g(p)=\log \left(\frac{p}{1-p}\right) \\
g(p)=\Phi^{-1}(p)
\end{gathered}
$$

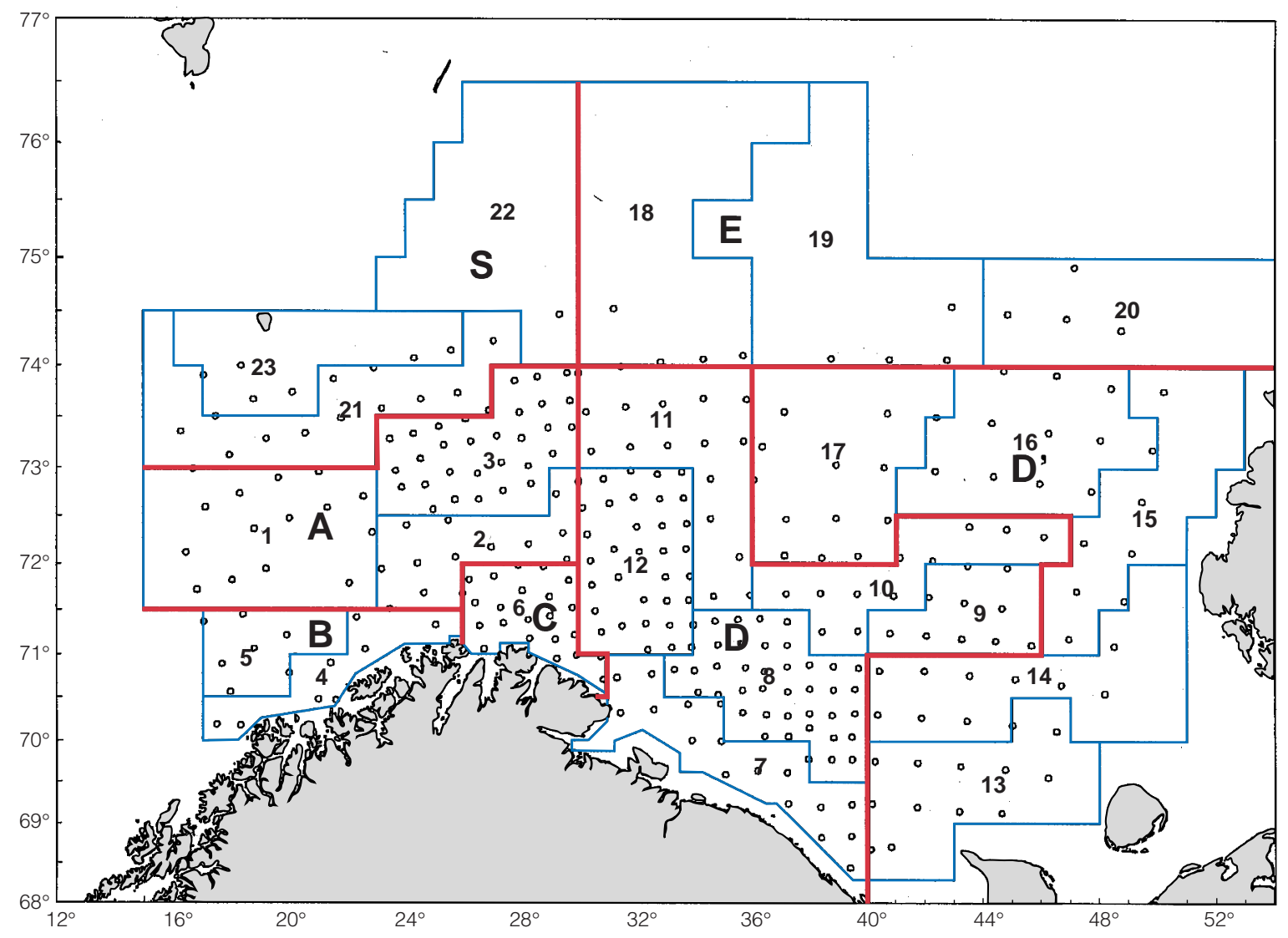

Fig. 1. Strata (numbers) and subareas (letters) used in the bottom trawl survey. Trawl stations sampled during the winter 1996 are shown. 
and

$$
g(p)=\log (-\log (1-p))
$$

where $\Phi^{-1}(p)$ in (2) is the inverse of the standard cumulative distribution function:

$$
\Phi(x)=(2 \pi)^{-1 / 2} \int_{-\infty}^{x} e^{\frac{-z^{2}}{2}} d z
$$

Samples for age, sex and maturity are clustered samples from a limited number of trawl stations. It has been shown that samples from one station show higher similarity compared to samples from neighbouring stations (i.e. there is intra-haul correlation). This has been shown for parameters such as mean weight or length and also for stomach content data (Pennington and Vølstad, 1994; Bogstad et al., 1995). This means that increasing the within station number of samples yields less new information than the sample size normally would indicate. This could lead to non-significant effects wrongly being included in the model. To avoid this problem the yearly sample size was reduced to:

$$
N_{\text {eff }}=e^{\frac{\log (N)+\log (n)}{2}}
$$

where the effective sampling size $N_{e f f}$ is a function of the total number of samples $(N)$ and the number of trawl stations with sampling of age, sex, maturation and size $(n) . N_{\text {eff }}$ and $N$ are shown in the following table:

\begin{tabular}{lrrrrrrrrrrrr}
\hline Year & 1985 & 1986 & 1987 & 1988 & 1989 & 1990 & 1991 & 1992 & 1993 & 1994 & 1995 & 1996 \\
\hline$N$ & 296 & 701 & 454 & 503 & 861 & 399 & 437 & 595 & 894 & 905 & 1011 & 798 \\
$N_{\text {eff }}$ & 43 & 108 & 83 & 96 & 132 & 62 & 67 & 116 & 176 & 186 & 211 & 227 \\
\hline
\end{tabular}

Samples are stratified in $5 \mathrm{~cm}$ length intervals and there were 5 samples in each interval. This was changed to 2 samples in each interval in 1993 and to 1 sample in each length interval in 1996. The number of stations with age sampling has been increased from 2 in each stratum to all stations in 1996. The highest (theoretical) degree of clustering would occur if all samples in one station were equal. Then one sample from each station would suffice and $N_{\text {eff }}=n$. The degree of clustering may vary from year to year and from station to station. The work by Pennington and Vølstad (1994) suggests that the effective sample sizes used in this study are on the conservative side.

The weighting factors used in the estimation of age-length keys (see Jakobsen et al., 1997) and also Morgan and Hoenig (1997) for a discussion on the handling of length stratified samples) are adjusted (multiplied by a constant) so that the sum of the weights equals $N_{\text {eff }}$.

The explanatory variables used in the analysis are described in the following table:

\begin{tabular}{lll}
\hline Year & class variable & 1985-96 \\
Length & continuous variable & length in cm \\
Age & class variable & age classified from otholith readings \\
Sex & class variable & female or male \\
Area & class variable & West $(\mathrm{A}, \mathrm{B}$ or C) or east (D) \\
St. log (VPA) & continuous variable & Log population numbers standardized within age groups \\
& & (mean $=0)$ \\
Growth & continuous variable & increase in mean length since previous survey by age and sex \\
\hline
\end{tabular}




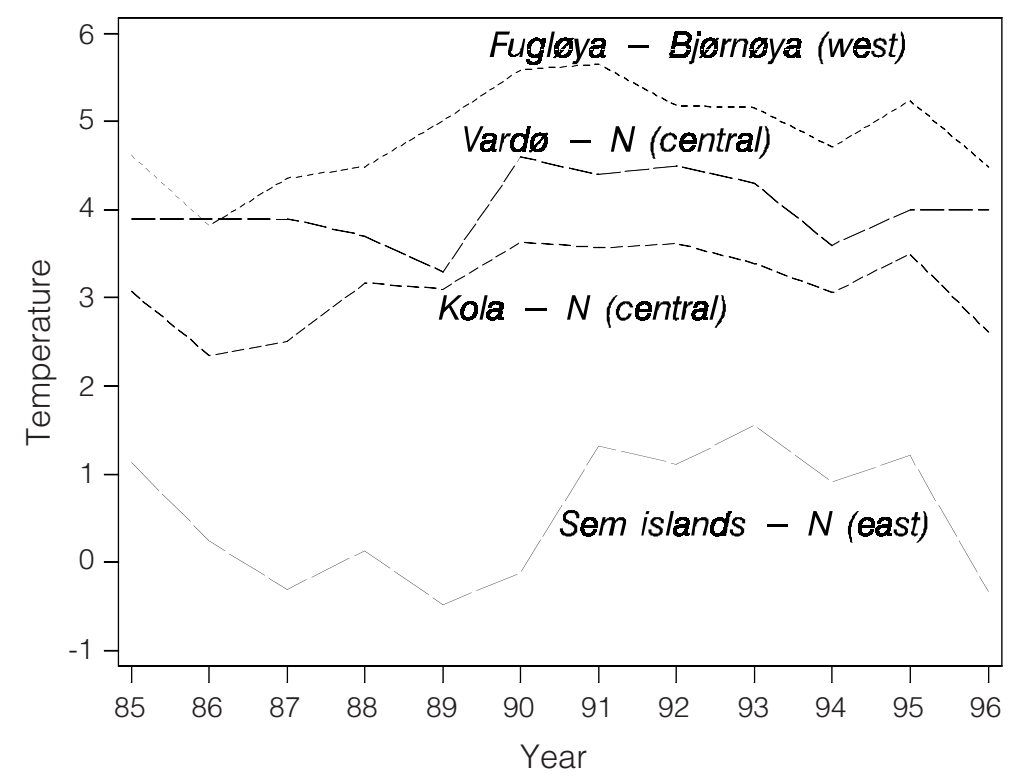

Fig. 2. Mean February temperatures from 4 hydro-graphical sections in the Barents Sea and relative position within the survey area.

The following second order interactions were also included:

\begin{tabular}{lcccccc}
\hline & Length & Age & Sex & Area & St. log VPA & Growth \\
\hline Length & & $*$ & $*$ & $*$ & & \\
Age & $*$ & & $*$ & $*$ & $*$ & $*$ \\
Sex & $*$ & $*$ & & $*$ & $*$ & $*$ \\
Area & $*$ & $*$ & $*$ & & $*$ & $*$ \\
St. $\log (\mathrm{VPA})$ & & $*$ & $*$ & $*$ & & \\
Growth & & $*$ & $*$ & $*$ & & \\
\hline
\end{tabular}

The third order interactions were St. $\log$ (VPA)*age*sex, growth*age*sex, st. $\log$ (VPA)*sex* area and growth*sex*area. The standardized $\log (\mathrm{VPA})$ was calculated as $\log$ population numbers by year and age standardized within age (by subtracting the mean value). The estimated population numbers used were taken from ICES (MS 1998).

All explanatory variables or their interactions were included or excluded using a stepwise method. At any step an adjusted chi-square statistic was calculated for all effects not already included in the model. The effect with the largest $\chi^{2}$ value was then included if it was significant at the 0.05 level. The new model was then fitted and non-significant effects were removed.

\section{Results}

The use of the logit link function (or logistic regression) performed slightly better than the other link functions, but without changing any of the conclusions on which effects best described the variations in observed maturity. Not an unexpected result as long as the functions define curves of quite similar shape and as long as the functional differences are much smaller than the variance in the model. The choice of a logistic regression model seems to be preferred for several species (Chen and Paloheimo, 1994; Munger et al., 1994). 
The following regression gave the best fit to the data $\left(r^{2}=0.4975\right)$ :

$$
\log \left(\frac{p}{1-p}\right)=I+l \cdot L+Y_{i}+A_{j}+B_{s, a}+s_{i, j} \cdot C_{a}
$$

where $I$ intercept

$l$ length in $\mathrm{cm}$

$L \quad$ length parameter

$Y_{i} \quad$ year effect in year $i$

$A_{j} \quad$ age effect for age $j$

$B_{s, a}$ interaction effect of sex $s$ in area $a$

$s_{i, j} \quad$ standardized $\log$ population numbers in year $i$ age $j$

$C_{a} \quad \log$ population numbers parameter for area $a$

The relatively low degree of variation explained by the model should be viewed in light of the reduced effective sampling size. Using full sample size the model estimation resulted in $r^{2}=0.6197$. The goodness of fit test (Hosmer and Lemeshow, 1989) did not produce significant results (no reason to reject the model including the choice of the logit as link function). The maximum likelihood estimates of the parameters are shown in Table 1.

The computer software used (SAS Institute Inc., 1996) allowed for "forcing" effects into the model and handling the remaining effects in a stepwise manner. This allowed for handling one of the problems with stepwise regressions: a stepwise inclusion allows for inclusion of only one effect at a time while two other effects may contribute more when both are included in a model. No such problem seemed to occur in these analyses and most interactions seemed to perform slightly worse than the main effects.

As expected individual length was the most important explanatory variable. The growth in the

TABLE 1. Summary statistics for the logistic regression.

\begin{tabular}{lcrcrc}
\hline \hline & $\begin{array}{c}\text { Parameter } \\
\text { DF }\end{array}$ & $\begin{array}{c}\text { Standard } \\
\text { estimate }\end{array}$ & $\begin{array}{c}\text { Chi-square } \\
\text { deviation }\end{array}$ & statistic & $\mathrm{P}$ \\
\hline$I$ & 1 & -6.9641 & 1.1588 & 36.1163 & 0.0001 \\
$L$ & 1 & 0.1264 & 0.0161 & 61.2678 & 0.0001 \\
$Y_{85}$ & 1 & 2.0560 & 0.7490 & 7.5342 & 0.0061 \\
$Y_{86}$ & 1 & 3.2755 & 0.4820 & 46.1852 & 0.0001 \\
$Y_{87}$ & 1 & 2.8711 & 0.4970 & 33.3733 & 0.0001 \\
$Y_{88}$ & 1 & 2.8707 & 0.4317 & 44.2211 & 0.0001 \\
$Y_{89}$ & 1 & 2.8767 & 0.4347 & 43.7849 & 0.0001 \\
$Y_{90}$ & 1 & 3.0901 & 0.5600 & 30.4437 & 0.0001 \\
$Y_{91}$ & 1 & 2.4383 & 0.7118 & 11.7356 & 0.0006 \\
$Y_{92}$ & 1 & 1.7862 & 0.5745 & 9.6678 & 0.0019 \\
$Y_{93}$ & 1 & 1.7472 & 0.4600 & 14.4298 & 0.0001 \\
$Y_{94}$ & 1 & 1.1251 & 0.3960 & 8.0739 & 0.0045 \\
$Y_{95}$ & 1 & 1.0126 & 0.3327 & 9.2647 & 0.0023 \\
$Y_{96}$ & 0 & 0.000 & & & \\
$A_{3}$ & 1 & -4.1927 & 0.7749 & 29.2739 & 0.0001 \\
$A_{4}$ & 1 & -3.0200 & 0.6713 & 20.2412 & 0.0001 \\
$A_{5}$ & 1 & -2.0662 & 0.6178 & 11.1876 & 0.0008 \\
$A_{6}$ & 1 & -0.9400 & 0.5902 & 2.5368 & 0.1112 \\
$A_{7}$ & 0 & 0.0000 & & & \\
$B_{\text {females, west }}$ & 1 & 0.4949 & 0.3293 & 2.2583 & 0.1329 \\
$B_{\text {females,east }}$ & 1 & -0.2291 & 0.2816 & 0.6622 & 0.4158 \\
$B_{\text {males, west }}$ & 1 & 1.4430 & 0.3196 & 20.3797 & 0.0001 \\
$B_{\text {males, east }}$ & 0 & 0.0000 & & & \\
$C_{\text {west }}$ & 1 & 0.2187 & 0.1335 & 2.6844 & 0.1013 \\
$C_{\text {east }}$ & 1 & 0.4064 & 0.1682 & 5.8371 & 0.0157 \\
\hline & & & & &
\end{tabular}



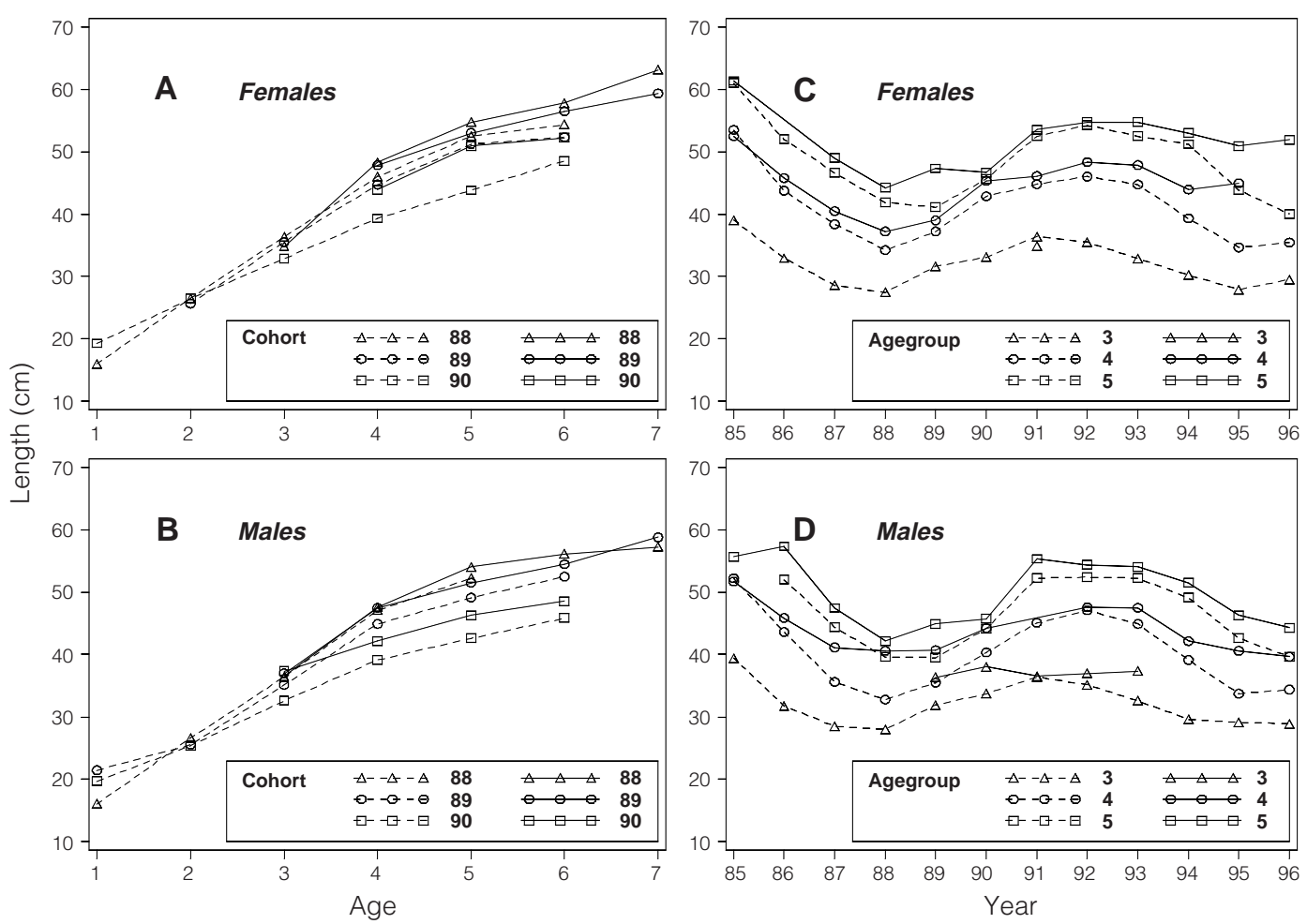

Fig. 3. Left: Mean length at age for the 1988, 1989 and 1990 year-class. Mean length of females (A) and males (B) for age groups 1-7 for both immature and mature fish are shown. Right: Mean length at ages 3-5 for females (C) and males (D) both immature and mature fish.

population varies between years. In Fig. 3 are mean length at age for the cohorts 1988-90 shown together with mean length at age for all the years. The period 1988-90 shows an increase in growth, but as seen from the length by cohort plots the 1988 year-class was able to maintain a higher growth rate than the younger ones through the decline in growth conditions in the 1990s.

The other continuous variable used in the models was the standardized $\log (\mathrm{VPA})$. Log population numbers are shown in Fig. 4 (A and B). They demonstrate clearly the impact of the strong 1983 and 1990 year-classes. The overall higher overall abundance towards the end of the period is causing most of the standardized log population numbers for a cohort to increase with age (Fig. 4, C and D).

Predicted proportions mature at age by area and sex for the years 1990 and 1996 are shown in Fig. 5; 1990 and 1996 represent the extremes within this short time series and were used to illustrate the variations in maturity. Curves connect minimum and maximum observed length within age, sex and area.

The standardized $\log$ (VPA) numbers and growth are the only explanatory variables not observed directly during the surveys. The growth rate was calculated as observed differences in mean length since the previous survey, while the standardized $\log$ (VPA) numbers can be viewed as being independent of the survey. The last assumption is only an approximation due to the fact that for the last 2-3 years, the VPA estimates have not converged.

Abundance (standardized $\log$ (VPA) numbers) showed a significant effect and the interaction with area further improved the fit. The abundance effect could be replaced with a growth effect (without interaction), but this gave a slightly poorer fit.

The year and age effects are presented in Fig. 6 . The age effects have a remarkable trend. Increasing the age one year shifts the maturity ogive to the left with close to a constant value. 

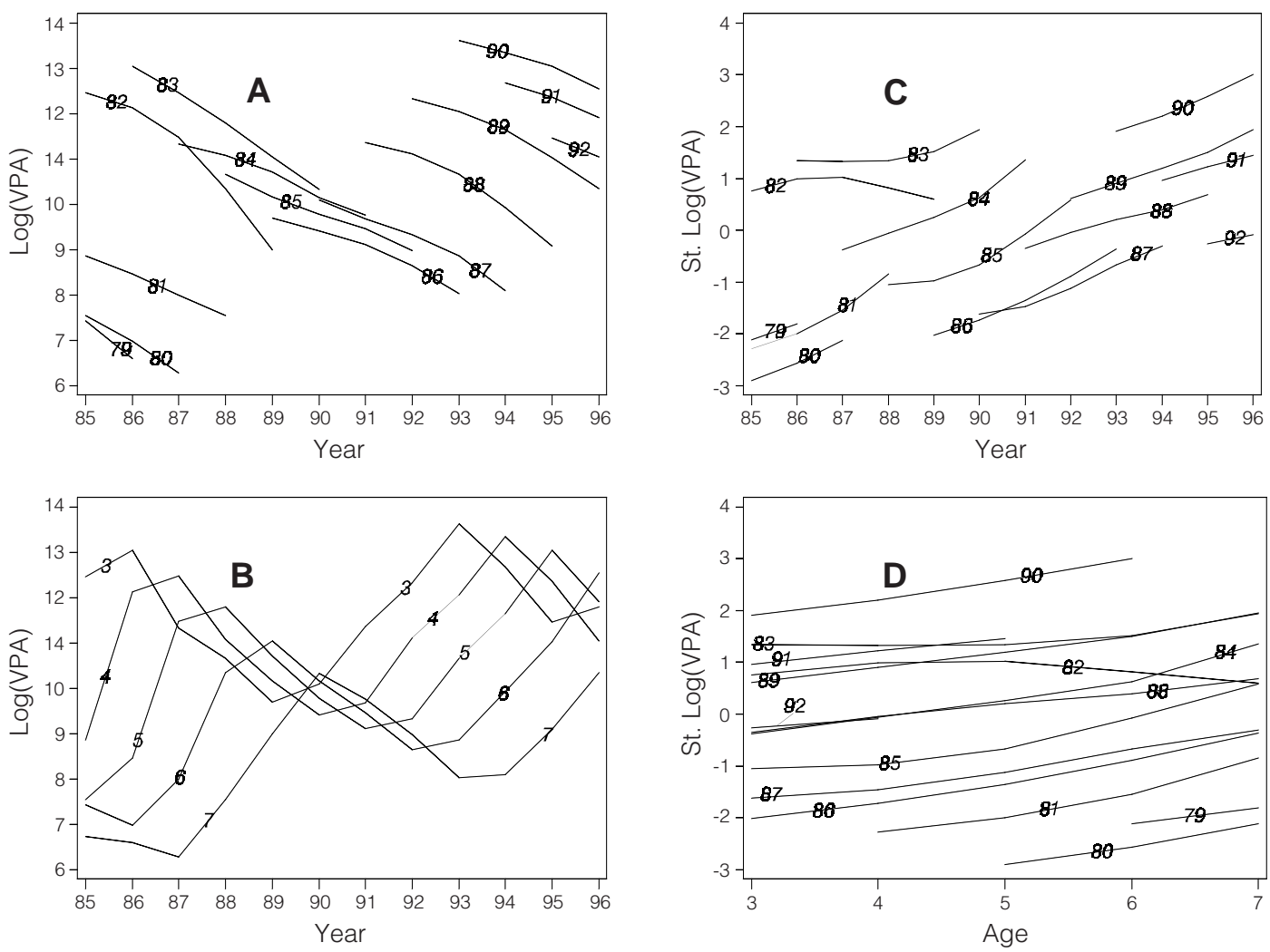

Fig. 4. Log population numbers (Log(VPA)) by cohort for the years 1985-96 (A), $\log (\mathrm{VPA})$ by age groups 3-7 for the years 1985-96 (B), standardized Log(VPA) by cohort for the years 1985-96 (C) and standardized $\log ($ VPA) by cohort for the age groups 3 to 7 (D).

\section{Discussion}

The Barents Sea as a habitat for haddock shows large fluctuations in environmental conditions (see also Fig. 2). These fluctuations, together with the effects of varying competition (density dependent effects), are causing the large variations in growth and size seen in Fig. 3. The abundance of haddock was at a medium to low level in the late-1980s and the increase in growth should be more related to the increasing temperatures and prey abundance than to any density dependent effects. It is reasonable to believe that the good growth condition was the major cause for the very good 1990 recruitment. The very large 1990 year-class together with reduced temperature lead to the decline in growth observed in the later years.

Length (or size) is the dominant factor determining maturity in haddock and with the observed variations it is clear that the size information also contains information on overall growth conditions including environmental factors and density dependent effects.
The estimated model in this work predicts a reduction in proportions matures of up to $25 \%$ if the length is reduced by $10 \mathrm{~cm}$. This means that changes in mean length itself explain quite a lot of the observed variation in maturity.

The model showed a distinct age effect. Keeping other effects constant the effect of being one year older shifts the maturity ogive to the left (on a length axis) and there is a higher probability of maturing. This one year increase effect is close to a constant for proportions in the vicinity of 0.5 .

The inclusion of a year effect is interesting from a model fitting perspective, but can be less satisfying when looking for underlying mechanisms causing changes in the proportions mature. Such mechanisms could be related to changes in yearclass strength, growth conditions or geographic distribution. The strong year effect in this model could not be replaced with any of the other explanatory variables or interactions between these. The effect start out at a high level up to 1990 and shows a decrease since then. As mentioned earlier 


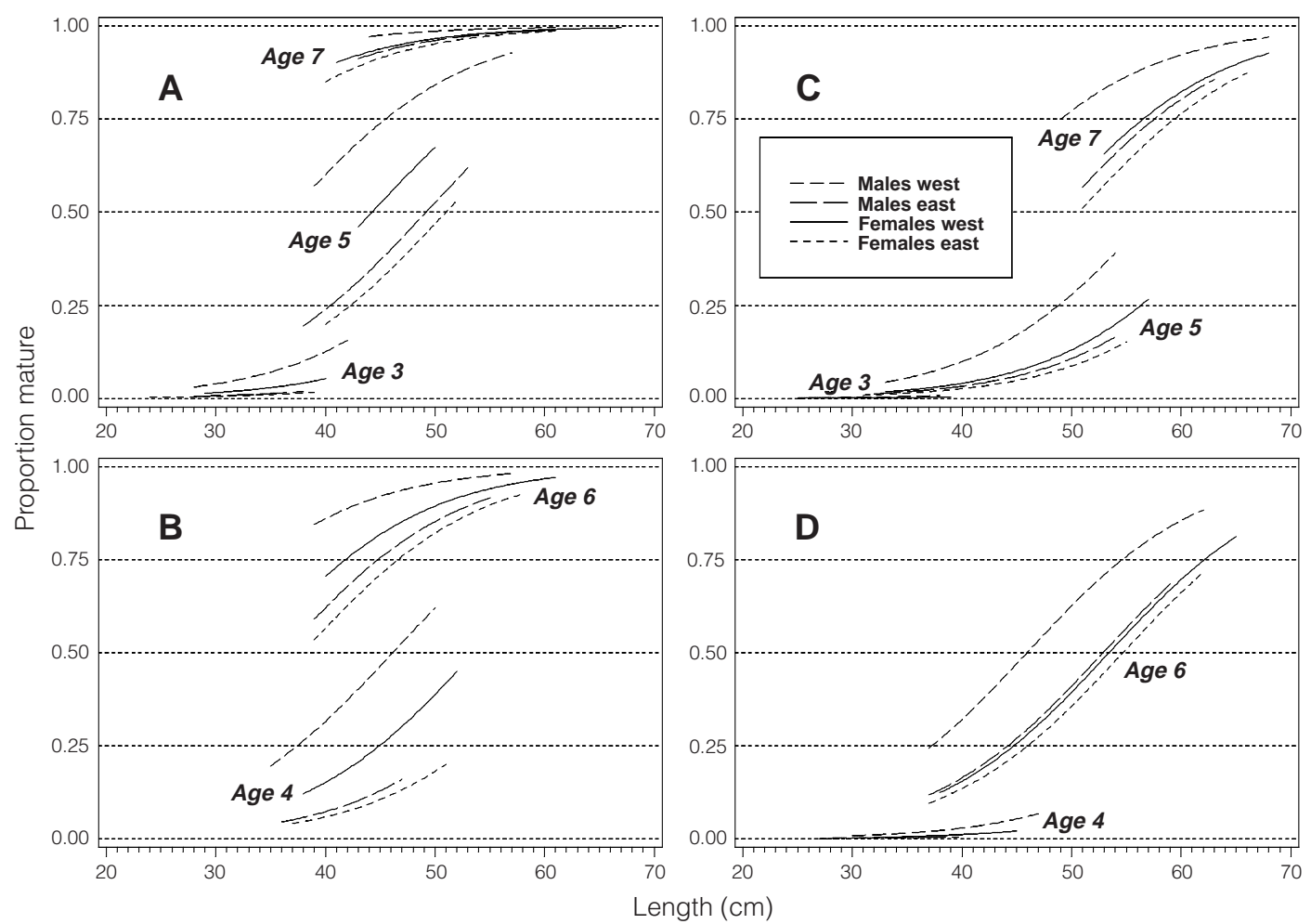

Fig. 5. Predicted maturity ogives for 1990 (age groups 3, 5 and 7 in A, age groups 4 and 6 in B) and predicted maturity ogives for 1996 (age groups 3, 5 and 7 in $\mathbf{C}$, age Groups 4 and 6 in D). Separate curves predicted for each area and sex.
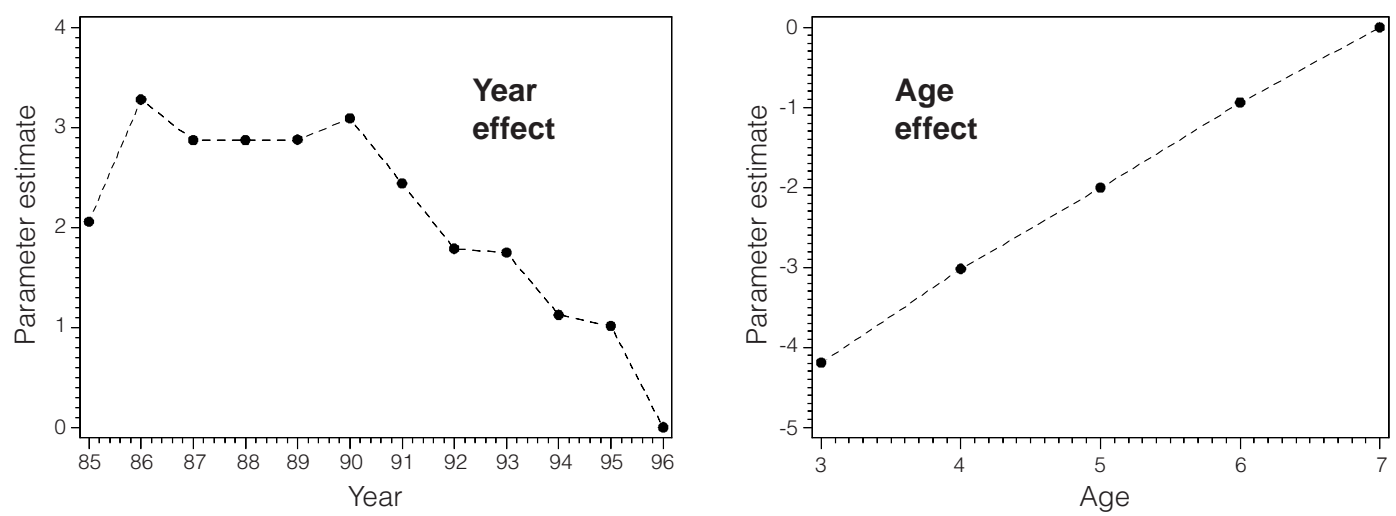

Fig. 6. Estimated year and age effects (numbers given in Table 1).

this coincides with the increased abundance caused by the 1990 year-class and a reduction in temperatures. Note however that the temperatures were at very low levels in 1986-87 when the year effect was high. Further insight in the mechanisms that is causing this year to year trend could be gained by including temperature effects and other environmentally linked effects in the modelling.
The growth effect did not perform very well compared with the other effects included in the models. As pointed out earlier, variations in growth are already partially embedded in the observed length.

The interaction effect between age and growth rate did not perform very well either. Such an 
interaction is equal to allowing different growth effects between different age groups. As long as both the length at age and also the proportions of repeat spawners vary, the assumption of a linear effect can again be violated.

The interaction between standardized log population numbers and area indicated that the difference between areas was larger in times of higher abundance. That is: at higher abundance with poorer growth conditions the longer distance from the eastern area to the spawning areas in the west could be of more importance than in years with better conditions.

In the model the interaction between area and sex suggests that the distance to the spawning areas is of importance (the area effect is larger for males than for females). As the spawning grounds are in the west the difference observed between areas are quite reasonable. Any spawning migration starting more than two months before spawning will lead to an increase in the observed proportions mature in the west. The difference between the sexes could then be caused by males migrating to the spawning grounds earlier than the females.

Models that estimate or predict proportions mature are of importance in assessment work. The given model should be quite useful as a tool for improving the current year estimation of maturity and spawning biomass of haddock in the Barents Sea. Another important part of assessment work deals with short term and medium term predictions of variations in maturity. The model presented in this study will only be able to predict maturation based on predictions of some of the explanatory variables. That is: fish lengths used in the model are observed and need to be replaced with predicted length (possibly from a growth model). Similarly there will be a need for predicting the year effect. No other explanatory variables could replace this effect, but it could possibly be modelled as a time series. Future work following up this study should focus on replacing the year effect through the inclusion of other explanatory variables and possibly also reformulating the model and its underlying assumptions.

\section{References}

BEACHAM, T. D. 1983. Variability in size and age at sexual maturity of haddock (Melanogrammus aeglefinus) on the Scotian Shelf in the Northwest Atlantic Ocean. Can. Tech. Rep. Fish. Aquat. Sci., 1168.

BOGSTAD, B., M. PENNINGTON, and J. H. VØLSTAD. 1995. Cost-efficient survey designs for estimating food consumption by fish. Fisheries Research. Amsterdam, 23(1-2): 37-46.

CHEN, Y., and J. E. PALOHEIMO. 1994. Estimating fish length and age at $50 \%$ maturity using a logistic type model. Aquat. Sci., 56(3): 206-219.

HOSMER, D. W. Jr., and S. LEMESHOW. 1989. Applied Logistic Regression. New York: John Wiley \& Sons, Inc.

ICES. MS 1998. Report of the Arctic Fisheries Working Group. ICES C.M. Doc., No. Assess:2.

JAKOBSEN, T., K. KORSBREKKE, S., MEHL, and O. NAKKEN. MS 1997. Norwegian combined acoustic and bottom trawl surveys for demersal fish in the Barents Sea during winter. ICES C.M. Doc., No. $\mathrm{Y}: 17$.

KOVTSOVA, M. V. MS 1993. Growth rate and maturation of Arcto-Norwegian haddock in 19871990. ICES C.M. Doc., No. G:58

MORGAN, M. J., and J. M. HOENIG. 1997. Estimating maturity-at-age from length stratified sampling. $J$. Northw. Atl. Fish. Sci., 22: 51-63.

MUNGER, C. R., G. R. WILDE, and B. J. FOLLIS. 1994. Flathead catfish age and size at maturation in Texas. N. Am. J. Fish. Manage., 14(2): 403-408.

NELDER, J. A., and R. W. M. WEDDERBURN. 1972. Generalized linear models. J. Roy. Stat. Soc., Series A, 135: 761-768.

PENNINGTON, M., and J. H. VØLSTAD. 1994. Assessing the effect of intra-haul correlation and variable density on estimates of population characteristics from marine surveys. Bio-metrics, 50: 725-732.

SAS Institute Inc. 1996. SAS/STAT ${ }^{\circledR}$ Software: Changes and Enhancements through Release 6.11, Cary, NC: SAS Institute Inc., 1996. 1104 p.

SOLEMDAL, P., T. KNUTSEN, and H. BJOERKE. 1989. Spawning areas and spawning period of the NorthEast Arctic haddock (Melanogrammus aeglefinus L.). HELP Havforskning-sinst. Egg-larveprogram., 25.

SOLEMDAL, P., N. MUKHINA, T. KNUTSEN, H. BJOERKE, and P. FOSSUM. MS 1997. Maturation, spawning and egg drift of ArctoNorwegian haddock (Melanogrammus aeglefinus). Presented at the Fisheries Society of the British Isles Annual Symposium. Galway (Ireland), 8-11 July 1997.

TEMPLEMAN, W., V. M. HODDER, and R. WELLS. 1978. Sexual maturity and spawning in haddock, Melanogrammus aeglefinus, of the southern Grand Bank. ICNAF Res. Bull., 13: 53-65.

TORMOSOVA, I. D. 1983. Variation in the age at maturity of the North Sea haddock, Melanogrammus aeglefinus (Gadidae). J. Ichtyol., 3: 68-74. 
